\title{
FORMAÇÃO DOCENTE: \\ O ANALÓGICO E O DIGITAL EM DEBATE
}

\author{
Juliana Cristina Faggion Bergmann ${ }^{1}$ \\ ORCID: 0000-0002-0535-5279 \\ LuANa Bottcher SBeghen ${ }^{2}$ \\ ORCID: 0000-0002-4707-5101 \\ Kadhiny Mendonça de Souza Policarpo ${ }^{3}$
}

ORCID: 0000-0002-2097-6647

Maria Paula Cruz Fonseca ${ }^{4}$

ORCID: 0000-0002-2725-0064

Gabriela MarÇal Nunes 5

ORCID: 0000-0003-0075-4649

1 Doutora em Sciences du Langage pela Université Lumière Lyon 2 - França, professora do Programa de Pós-Graduação em Educação e do departamento de Metodologia do Ensino da Universidade Federal de Santa Catarina, líder do grupo de pesquisa Tema Didático (CNPq/UFSC. E-mail: juliana. bergmann@ufsc.br.

2 Graduanda do curso de Letras - Espanhol pela Universidade Federal de Santa Catarina (UFSC) e integrante do grupo de pesquisa Tema Didático (CNPq/UFSC). E-mail: (luanasbeghen@gmail.com).

3 Mestranda em Educação no programa de Pós-Graduação em Educação (Bolsista CAPES) - UFSC. Graduada em Letras Espanhol (Licenciatura) pela Universidade Federal de Santa Catarina. Integrante no grupo de pesquisa Tema Didático (CNPq/UFSC). E-mail: (kadhinymendonca@gmail.com).

4 Licenciada em Letras - Francês pela Universidade Federal de Santa Catarina. Integrante no grupo de pesquisa Tema Didático (CNPq/UFSC). E-mail: (mpaulaf94@gmail.com).

5 Mestranda em Educação no programa de Pós-Graduação em Educação (Bolsista CAPES) - UFSC. Graduada em Letras Espanhol (Licenciatura e Bacharelado) pela Universidade Federal de Santa Catarina. Graduanda no curso de Pedagogia na Universidade Federal de Santa Catarina. Integrante no grupo de pesquisa Tema Didático (CNPq/UFSC). E-mail: (mnunesgabriela@gmail.com). 
Resumo: O relato que apresentamos nesse texto retrata e analisa uma experiência de extensão para a formação docente, a fim de discutir a apropriação de mídias, especialmente aplicativos e jogos, por professores da rede pública municipal e estadual. Para isso, propõe uma ação de extensão que discuta a teoria especializada intrinsecamente relacionada à prática. Nela, os participantes do curso, no qual teve a duração de $36 \mathrm{~h}$ e que foi ofertado pela Escola de Extensão da UFSC, analisaram aplicativos disponíveis no mercado, assim como planejaram outros mais adequados às suas necessidades e a de seus alunos, conheceram novas ferramentas e exploraram novas metodologias. A ação mostrou um aumento no nível de interesse dos professores pela utilização de recursos didáticos inovadores, digitais ou analógicos.

Palavras-chave: Recursos Didáticos. Extensão. Aplicativos. Gamificação. Formação de professores.

\title{
TEACHER TRAINING: THE ANALOG AND THE DIGITAL IN DISCUSSION
}

\begin{abstract}
The report presented in this text shows and analyzes a teacher formation experience that discuss the medias appropriation, in special applications and games, by teachers from public schools. For that, it purposes an extension action that discuss the theory connected with the practice. In that experiment, with 36 hours duration and offered by Escola de Extensão from UFSC, the participants analyzed the available applications, as well thought of others possible apps that would be more useful for the teacher and the student's necessities, they also got to know new tools and explored news methodologies. The action showed an increase in the teacher's interest level in using new, digital or analog, pedagogical resources.
\end{abstract}

Keywords: Pedagogical Resources. Extension. Applications. Gamification. Teacher Training.

\section{FORMACIÓN DOCENTE: LO ANALÓGICO Y LO DIGITAL EN DEBATE}

Resumen: El relato presentado en este texto retrata y analiza una experiencia de extensión de formación docente que discute la apropiación de los medios, especialmente aplicaciones y juegos, por parte de maestros de las escuelas públicas municipales y estatales. Para ello, propone una acción de extensión que discute la teoría especializada intrínsecamente relacionada con la práctica. En él, lo cual tuvo 36h de duración y fue ofrecido por la Escola de Extensão de UFSC, los participantes analizaron las aplicaciones disponibles en el mercado, y planearon otras que se adaptaban mejor a sus necesidades y las de sus estudiantes, aprendieron nuevas herramientas y exploraron nuevas metodologías. La acción mostró un aumento en el nivel de interés de los docentes por el uso de recursos didácticos digitales o analógicos innovadores.

Palabras claves: Recursos Didácticos. Extensión. Aplicaciones. Gamificación. Formación Docente. 
A experiência de extensão que relatamos e analisamos neste artigo foi elaborada pelo grupo de Pesquisa Tema Didático ${ }^{6}$, a partir de suas experiências e discussões, em parceria com a Escola de Extensão da Universidade Federal de Santa Catarina (UFSC), ação da Pró-reitoria de Extensão para a promoção do diálogo entre universidade e comunidade em suas diversas áreas.

Assim, no ano de 2019, tivemos a oportunidade de ministrar o curso de extensão APPlicando recursos tecnológicos em sala de aula, cujo objetivo principal era estimular um diálogo sobre diferentes abordagens teóricas e práticas utilizando, para isso, aplicativos em sala de aula como complemento ao ensino-aprendizagem de línguas estrangeiras.

Os encontros foram ministrados em dois momentos: com aulas expositivas e práticas. Se esperava que ao final do curso os participantes fossem capazes de desenvolver uma proposta didática que abordasse um dos pontos discutidos, de maneira que fosse coerente ao seu contexto e realidade dentro de sala de aula. $\mathrm{O}$ curso ocorreu no mês de fevereiro de 2019 no campus Florianópolis da UFSC e a participação gerou um certificado (30h), ponto importante para o plano de carreira dos professores.

\section{ERA DIGITAL}

As pesquisas atuais que discutem a contemporaneidade e sua influência tecnológica, a chamada Era Digital (BANNEL et al., 2016; NUNES et al., 2019; PÉREZ GÓMEZ, 2015; SCHMIDT e COHEN, 2013; VEEN e VRAKKING, 2009), são unânimes em apontar a presença massiva dos dispositivos móveis no dia a dia dos indivíduos, independente de sua idade, permitindo a que cada um seja ao mesmo tempo produtor e consumidor de conteúdo (VÁZQUEZ-CANO e SEVILLANO, 2019).

O fato - incontestável - desta onipresença tecnológica na sociedade cria uma grande pressão no ambiente educativo, gerando como consequência uma dualidade de reações: o apoio incondicional ao digital por um lado (vindo em sua maioria por parte dos alunos) e a recusa, por vezes também incondicional, do digital por outro (esta última, geralmente vinda da parte de professores e equipe de direção). Com esse panorama, fica claro o grau de tensão que envolve o tema e talvez explique parte da dificuldade de integração das tecnologias digitais nestes ambientes.

Sabemos que a questão do uso de dispositivos móveis em contexto escolar é, ainda, bastante controversa e não apenas no Brasil. Diferentes países discutem

6 https://temadidatico.ufsc.br/ 
seu uso dentro da escola, proibindo-o, inclusive, em vários casos. A justificativa para esta posição é o seu potencial de distração e uso indevido que tais aparelhos podem causar. No entanto, apesar de compreender tal posicionamento, acreditamos que é exatamente na escola em que o espírito crítico e analítico do indivíduo deve ser estimulado e, por isso, é justamente nela que tais questionamentos devem submergir para que se construa, coletivamente, uma compreensão sobre os limites, desafios e potencialidades do digital que, inegavelmente, está presente na vida de todos fora do ambiente escolar. Dessa forma, para que seja possível um ambiente de análise, discussão e compreensão dos recursos digitais na escola, torna-se fundamental uma integração efetiva de tecnologias, que esteja atrelada às atividades planejadas pelo professor, dentro de uma metodologia que considere todo o potencial dos recursos digitais em consonância com os objetivos de aprendizagem do grupo.

\section{ESCOLA ANALÓGICA OU DIGITAL?}

Ainda que muitos docentes reconheçam o papel fundamental que as mídias digitais trazem para o campo educacional, existe uma resistência em aplicar as novas tecnologias em sala de aula. Essa resistência se deve por muitos fatores, mas dentre os mais comuns podemos destacar a insegurança, seja por não se sentir seguro de possuir as competências e habilidades necessárias para trabalhar com os artefatos digitais, seja por temer que seu papel de professor seja substituído ou desnecessário.

$\mathrm{O}$ atual cenário se explica pelo fato de que a maior parte dos alunos se desenvolveu com as tecnologias e sabem manipulá-las de maneira eficiente, muitas vezes, melhor do que seus professores. Pérez Gómez (2015) sinaliza esse fato como uma "inversão dos papéis na vida social familiar e escolar, ao converter os alunos em especialistas digitais e os adultos em aprendizes em tempo parcial dos nossos jovens peritos digitais" (PÉREZ GÓMEZ, 2015, p. 27). Além disso, os artefatos digitais transformaram os interesses e comportamentos dos jovens atuais, surgindo, como afirma Kenski (2003, p.7), novas formas de aprendizagens abertas, não lineares, mutáveis e criativas, incomparáveis com aprendizagens em que colocam o professor como o centro e o aluno como receptor do conhecimento.

Isso constitui um desafio para o campo da educação, pois o professor, por seu papel fundamental de planejador e mediador do processo de construção da aprendizagem do aluno, recebe grande pressão social, sendo continuamente cobrado pela presença ou ausência do digital em sala. Por um lado, alunos e parte 
da sociedade apoiando (e exigindo) a entrada massiva dos dispositivos na escola, por outro, o professor resistindo à imposição a que é submetido.

Apesar das grandes críticas que sofre por não haver, ainda, integrado o digital nas atividades pedagógicas, ao longo do tempo esta resistência do professor, consciente ou inconscientemente, tem exercido uma interessante posição de contraponto, fazendo-nos refletir sobre a importância do analógico, do desligar-se do virtual, do brincar. Nos sentimos, muitas vezes, de tal forma invadidos pelo digital que o universo analógico da escola é um espaço de respiro.

Assim, estamos em uma busca pelo equilíbrio, de uma integração consciente da tecnologia em sala de aula, com fins didático-pedagógicos, que estimule a criticidade dos alunos e que os permita compreender os potenciais, mas também os riscos, do mundo virtual.

Entendemos que passar a utilizar o digital não é apenas uma questão de aprender a manipular os dispositivos, mas também uma mudança importante na metodologia de ensino e dos processos de aprendizagens. Essa nova metodologia precisa, então, corresponder às necessidades dos envolvidos, baseada em um ambiente mais aberto, na troca de informações e na aprendizagem coletiva, com objetivo de formar cidadãos autônomos, responsáveis pelas suas próprias ações e escolhas.

É dentro desse contexto, de transformações e novas exigências, que muitos professores vêm percebendo o potencial em aliar as tecnologias à sua prática pedagógica e, também, na importância de repensar novas metodologias em proveito de ensino e aprendizagens mais significativas. Durante o curso de extensão oferecido por nós e que iremos apresentar neste artigo, notamos que o interesse pela manipulação dos artefatos digitais, bem como a aplicação de atividades práticas com o uso de aplicativos e plataformas, foram os aspectos que mais despertaram o interesse dos professores. Uma pesquisa realizada em 2018 pelo Centro Regional de Estudos para o Desenvolvimento da Sociedade da Informação (Cetic.br) mostrou que o interesse pelo o uso das tecnologias em atividades educacionais está crescendo comparado aos últimos anos. Em 2018, 76\% dos professores utilizaram a Internet para desenvolver ou aprimorar seus conhecimentos sobre o uso de tecnologias nos processos de ensino e de aprendizagem.

Conscientes, portanto, da mudança metodológica importante que a entrada da tecnologia provoca no universo escolar, propusemos uma reflexão conjunta com os professores na busca por esse equilíbrio entre o digital e o analógico, apresentando propostas com o uso de aplicativos, ao mesmo tempo em que discutimos como a gamificação (BURKE, 2015; GEE, 2009; KAPP, 2012) pode nos ajudar a repensar o planejamento de diferentes atividades analógicas. 


\section{CONTEXTO: PROPOSTA DE EXTENSÃO}

Aspectos práticos influenciam muito para o índice de participação em um curso de extensão como o que foi promovido. Ele aconteceu na Universidade, ou seja, fora do ambiente de trabalho do professor, o que dificulta o deslocamento, e em um momento em que as aulas das escolas públicas da rede municipal e estadual já haviam recomeçado. Neste sentido, compreendemos que, para além do interesse (ou a falta dele) pela temática abordada, tais fatos determinam a possibilidade ou não de participação. No nosso caso, a motivação para discutir e refletir sobre o tema que propúnhamos ficou demonstrada com o convite, ainda durante o curso, para uma série de encontros de compartilhamento das discussões, que ocorreram ao longo do mesmo ano reunindo um total de cerca de 250 professores da rede pública.

Assim, dos 04 encontros inicialmente planejados, outros 06 encontros extras ocorreram, com o objetivo de refletir sobre as tecnologias na escola a partir das perspectivas teórica e prática, além de discutir a gamificação como implementação dessas tecnologias de maneira analógica. Desta forma esses novos encontros, menos extensos, abordaram temas como Era digital, A escola na Era digital, Aplicativos móveis como recursos didáticos digitais e Gamificação.

Do ponto de vista dos recursos físicos e de infraestrutura, para a totalidade dos encontros de extensão foi utilizado o BYOD (Bring Your Own Device), no português 'traga o seu próprio dispositivo', uma ação pensada para mostrar ao mesmo tempo que os seus próprios dispositivos móveis podem ser a chave para as atividades a serem desenvolvidas em suas aulas, para que baixassem (ou aprendessem a baixar) alguns dos aplicativos citados durante a extensão que lhes interessasse, para que conhecessem melhor seus aparelhos de smartphone (ou tablet) e se sentissem mais confiantes para usá-lo para fins acadêmicos, além de conhecermos melhor seus níveis de aprofundamento tecnológico.

Dados apresentados pela pesquisa TIC Educação 2018 ${ }^{7}$, da Cetic.br, mostraram que naquele ano $51 \%$ dos professores acessaram a internet de seu próprio celular para desenvolver atividades em sala de aula com seus alunos. A proposta do curso foi um sucesso e nos confirmou, na prática e através dos dados divulgados recentemente, o potencial deste tipo de método.

7 https://cetic.br/pesquisa/educacao/ 


\section{POSSIBILIDADES COM O DIGITAL NA ESCOLA}

O curso de extensão foi, assim, planejado para abranger aspectos teóricos e práticos da tecnologia na atualidade, trazendo para o grupo um debate que pudesse auxiliar a compreensão dos professores quanto a alguns aspectos chave do mundo digital, dos aplicativos e da gamificação. Iniciou-se com uma proposta de discussão sobre o que é a "era digital", como a escola se insere neste contexto e qual o seu impacto nas novas gerações, inicialmente a partir do compartilhamento das concepções dos participantes do curso e, em seguida, contrastando-as com a literatura especializada.

Esta introdução teórica serviu de base, também, para a introdução de um dos temas fundamentais da proposta que queríamos apresentar: o uso de aplicativos na escola como recursos didáticos digitais complementares e facilitadores do processo de aprendizagem. Os aplicativos ou Apps são softwares, ou seja, programas que ao serem instalados nos dispositivos móveis nos permitem executar uma ou várias funções, funcionando como um atalho virtual que nos leva aonde queremos ir (GARDNER e DAVIS, 2014). Quando em sala de aula, podem se converter em recursos didáticos digitais, seja através do BYOD ou utilizando aparelhos que a escola disponibiliza.

Esse olhar de Gardner e Davis (2014) traz à tona a realidade da possibilidade de uso de aplicativos em quase todos os aspectos da nossa vida: financeira, de locomoção, comunicação ou entretenimento são apenas alguns deles. A escolha sobre qual app utilizar, inclusive, conta muito sobre quem somos em um determinado momento de nossas vidas: como uma fotografia ou, como denominam os autores, uma "identidade app", uma "pegada digital". Pensando nisso em conjunto com as possibilidades do BYOD, o grupo desenvolveu uma atividade de (re)conhecimento do outro através da primeira tela de cada celular.

Assim, a atividade constou em apresentar o colega através dos aplicativos que ele tinha no celular, visto que cada indivíduo o utiliza e organiza-o na maneira que lhe é mais prática e coerente com as atividades que desempenha. Nesse sentido, se pode inferir que uma pessoa que tenha várias redes sociais, aplicativos de transporte alternativo e de edição de fotos em seu celular, utiliza o aparelho para desempenhar as atividades tais como se relacionar virtualmente, utilizar transportes alternativos e que tem interesse em fotografias. Entretanto, se uma pessoa tem apenas o whatsapp instalado no seu celular, significa que é uma pessoa que não está ligada às tecnologias e que a utiliza apenas para uma comunicação mais simples e direta. Logicamente, não era nosso objetivo traçar um perfil 
psicológico, bem definido e estruturado do indivíduo, mas tentar conhecer um pouco mais cada participante a partir de suas preferências e gostos.

Por mais que cada aparelho móvel possa ser personalizável de acordo com os aplicativos que compõem a sua tela, muitas vezes a decisão do usuário é limitada pelas decisões de programação do desenvolvedor do App, ou seja, muitas atividades só podemos realizar se o sistema nos permite. Sendo assim, Gardner e Davis (2014) dividiram os aplicativos em duas categorias, e a partir desta divisão, podemos ter mais clareza sobre como e por que utilizar um aplicativo como recurso didático digital.

O primeiro tipo de aplicativo de acordo com os autores é o App-dependente, aquele que leva a pessoa a ser dependente, em outras palavras, aqueles tipos de aplicativos que limitam e determinam os atos, escolhas e objetivos do usuário. Seriam aqueles que executam objetivos educativos tradicionais através do meio digital, que são apenas uma transposição do papel e caneta para a tela do celular, que não trazem nenhuma potencialidade.

Já o App-capacitador seria aquele que permite e que incita a buscar novas possibilidades, para que o usuário possa esboçar, publicar, tomar notas, se relacionar, criar e refletir. São aplicativos que despertam a autonomia, a criatividade, que desafiam os alunos, e que possibilitam a utilização de todas as mídias nas quais convergem no dispositivo móvel; podem potencializar a aprendizagem, sem limitar-se apenas a uma transposição.

Compreender estas relações de dependência ou autonomia em relação aos aplicativos pode ser uma das chaves para auxiliar na escolha dos aplicativos a serem trabalhados em sala, planejando a abordagem com base nas características, interesses e motivações de cada grupo de alunos. Para isso, é fundamental conhecer o aplicativo e analisar suas propostas, contrapondo-as aos objetivos pedagógicos dos alunos. Essa confrontação dirá se e qual recurso é o mais adequado para cada situação.

Desta forma, foi proposto ao grupo participante do curso uma análise de alguns aplicativos previamente selecionados, para que aspectos importantes do processo de diagnóstico pudessem ser levantados. Por ser um curso com ênfase no ensino-aprendizagem de línguas estrangeiras (LE), para esta etapa foram selecionados 06 aplicativos específicos para aprendizagem de LE, uma das temáticas mais populares das lojas de aplicativos: Busuu, Duolingo, ABA English, Babbel, Polly Lingual e LinguaLeo.

Para auxiliar na análise dos aplicativos pré-selecionados, foi apresentado aos professores participantes a Plataforma de Análise de Aplicativos de Línguas Estrangeiras ${ }^{8}$, cujo foco é tornar-se um meio de fácil acesso e otimização de análise

8 http://analisedeapps.sites.ufsc.br/ 
desses softwares, assim como a coleta e geração dos resultados. A Plataforma foi desenvolvida como continuação de um trabalho de estruturação de uma ficha analítica (NUNES, 2017) com pontos que devem ser levados em conta na análise de aplicativos de línguas estrangeiras. Além disso, tem como objetivo auxiliar professores no desafiador processo de escolha de um app que seja adequado para ser inserido como recurso didático de apoio às aulas presenciais.

Pensando nisso, a plataforma foi desenvolvida para oferecer aos professores uma otimização do processo de escolha. Para tanto, o site apresenta um survey com 09 categorias em que o professor, enquanto usa o aplicativo, responde e analisa as diferentes questões sobre ele. Cada categoria está relacionada com uma habilidade ou ponto específico que deve ser levado em consideração quando se propõe a usar um aplicativo com alunos em sala de aula, como seus dados técnicos, ano de desenvolvimento e ano de atualização, línguas trabalhadas no aplicativo e se existe qualquer tipo de cobrança financeira (NUNES e BERGMANN, 2019).

Ademais, os professores também tiveram a tarefa de analisar, com auxílio da plataforma, a interface gráfica do aplicativo e sua usabilidade. Pensando em converter aplicativos em material de apoio, a forma como o aluno navega deve ser fácil e sem interrupções ou distrações.

Também são analisadas as atividades apresentadas nos apps, assim, de forma individual, cada habilidade possui uma categoria em que o professor pode conhecer e avaliar como o aplicativo contempla, aborda e exercita cada uma das atividades de 04 habilidades requeridas no processo de aprendizagem de línguas - escrita, leitura, fala e audição - segundo o Marco Común Europeo de Referencia para Lenguas Extranjeras.

Da mesma maneira, a interatividade e acessibilidade presente nos aplicativos também são avaliadas, pois a interação entre usuário e usuário é de suma importância no momento de aprender uma língua, para tanto, a interação homem-máquina também se faz igualmente importante para que o processo de aprendizagem seja exitoso. Além do mais, por tratar-se de um software de um dispositivo móvel, que está em constante atualização, os recursos de acessibilidade para pessoas com necessidades especiais também se faz presente e muito importante, visto que é cada vez mais comum que crianças, jovens e adultos cegos, surdos ou com outros tipos deficiências sejam usuários desses dispositivos e, portanto, seu uso não deve ser restringido.

Para finalizar a análise, as categorias finais contemplam o feedback e relatos de experiências. Sabe-se que o feedback é uma peça essencial no processo de aprendizagem, podendo ser tanto um elemento estimulante quanto prejudicial. Nesse sentido, é necessário analisar as formas como ele aparece no aplicativo: se 
se faz presente apenas no momento de erro ou se também é visto nos momentos de acerto, se apenas indica o erro através de efeitos (visuais, sonoros etc), ou se reporta o erro e busca sanar a possível dúvida do usuário. Finalmente, na última categoria os professores podem relatar experiências com o aplicativo, ou ideias para fazer uso, além de reportar erros e críticas à plataforma.

Todas as respostas do survey ficam armazenadas e disponíveis para consulta de outros professores, ou seja, aquele professor que não disponibiliza de tempo para conhecer e analisar algum aplicativo, pode recorrer às análises já feitas, e comparar resultados, avaliando o aplicativo que julga ser mais adequado.

Para completar o processo, após as discussões sobre os prós e os contras de cada um dos apps analisados, foi proposto ao grupo de participantes que imaginassem como seria estruturado um "aplicativo ideal" para aprender línguas estrangeiras. Esta proposta tinha como principal objetivo fazer com que os participantes se colocassem em uma posição, ainda que fictícia, de desenvolvedores de um aplicativo, planejando cada um dos aspectos antes considerados importantes na avaliação dos apps já existentes.

O último dia teve como enfoque a demonstração de aplicativos e plataformas que podem ser utilizados para a criação de atividades educativas. $\mathrm{O}$ intuito não era o de restringir o uso de aplicativos em sala de aula para aqueles desenvolvidos especificamente para a aprendizagem de línguas estrangeiras. Ao contrário, a intenção era a de mostrar os potenciais do uso de apps desenvolvidos para outros fins que não os educacionais e de salientar que eles poderiam se transformar em recursos didático-pedagógicos, dependendo dos objetivos a serem trabalhados. No âmbito das próprias línguas estrangeiras, por exemplo, um aplicativo de deslocamento, com mapa, pode se transformar em uma atividade interessante de compreensão auditiva e de passeios virtuais locais ou por diferentes cidades do mundo.

Dessa forma, em um primeiro momento, realizamos uma discussão com o objetivo de compartilhar as experiências dos professores em relação ao uso de aplicativos em sala de aula. Para tal, questionamos se eles conheciam e se já haviam usado algum aplicativo em suas práticas pedagógicas. Alguns professores citaram ferramentas como a plataforma Kahoot, mas a maioria revelou não ter utilizado nenhuma em sala de aula. Entendemos que isso ocorre por muitos fatores, como a falta de orientação e/ou formação adequada para que os professores consigam enxergar uma proposta didática, as limitações de infraestrutura escolar (o que pudemos notar na fala de alguns professores durante o curso), como também a inabilidade de manipulação das tecnologias digitais. 
Em seguida, apresentamos 10 ferramentas (R code, Aurasma, Google Expedições, Realidade virtual, Kahoot, Podcast, Plickers, Padlet, Goconqr, Thinglink) aos professores, discutindo suas características e as possibilidades de atividades a serem desenvolvidas com cada um deles. Pudemos perceber que esta etapa no curso foi a que mais interessou os docentes, pois todos se mostraram muito curiosos e participativos. Contudo, notamos que a grande maioria gostaria de mais tempo de prática para aprender a utilizar as ferramentas.

Nesse ínterim de discussões, apresentações de diferentes perspectivas, contextos e aquisição de novos conhecimentos através dos aplicativos abordados no curso da Escola de Extensão, surgiu o interesse de aprofundamento no tema do analógico: é possível ainda trabalhar sem as tecnologias na Era Digital? Se sim, quais são as reformulações que estão sendo feitas nas metodologias para adequação aos novos perfis atencionais dos estudantes? Com base nisso, surge a proposta de uma formação aos docentes sobre uma dessas novas práticas pedagógicas - a gamificação - sem a utilização do digital, apresentada a seguir.

\section{NOVAS POSSIBILIDADES ANALÓGICAS NA ESCOLA}

Mesmo que falar em Era Digital pressuponha a utilização integral ou parcial de tecnologias digitais no cotidiano escolar, refletir sobre a reformulação e inovação nas abordagens analógicas continua sendo necessário. Segundo os dados da pesquisa TIC Educação 2018 realizada pelo Cetic.br sobre acesso à internet em ambiente escolar, foi constatado que, apesar de $98 \%$ das escolas em zona urbana terem acesso à internet, $43 \%$ das escolas rurais ainda não têm essa conectividade por falta de estrutura na região.

Além disso, dos 98\% citados das zonas urbanas, deve-se levar em consideração que o "acesso" pode referir-se a um ou poucos computadores disponíveis para toda a instituição - 33\% das escolas tem mais de 40 alunos por computador - ou que a conectividade wireless seja inacessível aos alunos, exemplificado pela baixa porcentagem onde apenas $6 \%$ das escolas deixam o acesso livre à rede, $66 \%$ tem uso controlado por senha e os alunos não podem se conectar e apenas $20 \%$ permitem o uso com conectividade restrita/com senha.

Não obstante, muitos professores também argumentam que, seja por questões de idade escolar (que envolvem o desenvolvimento social/motor nos anos iniciais) ou a construção de relações saudáveis com seus pares na adolescência, o trabalho e as atividades analógicas como o brincar, o construir, o modificar são fundamentais para um bom desenvolvimento cognitivo, social e motor para 
os estudantes, sendo, dessa maneira, a escolha pelo analógico não somente por falta de opções digitais, formação nas TIC ou infraestrutura, mas uma decisão tomada a partir de outras perspectivas pedagógicas. Com base neste panorama, formulam-se as metodologias ativas a partir de propostas que podem incluir ou não TIC, sendo o centro de seus objetivos desenvolver a autonomia do estudante frente à sua aprendizagem.

A gamificação por si mesma - porque há de se ressaltar que o termo abrange outra metodologia também, o Game Based Learning (GBL) - entra como uma abordagem que consiste na utilização de elementos dos games (mecânicas, estratégias, pensamentos) fora desse contexto de jogo, com a finalidade de motivar os indivíduos à ação, auxiliar na solução de problemas e promover aprendizagens (KAPP, 2012). É importante pontuar que ela pode aparecer tanto no contexto digital como no analógico, ambas abordagens tratadas durante o curso.

O engajamento ocorre através de elementos como atividades/desafios por módulos (que podem ser apresentados por temas ou níveis de dificuldade), criação de identidade (personificação), feedback rápido (oportunizando a mudança e aperfeiçoamento de estratégias conforme avanços ou retrocessos), resultados intrínsecos/extrínsecos, coletivo/individual, colaboração/competição, narrativa (desafios encaixados dentro de uma história) ou emergente (mais mecânico, ênfase em regras e parâmetros), espaço (interno ou externo), ambientação, metas/ objetivos claros (a não ser que o mistério, descobrir as regras faça parte da mecânica da atividade), Leaderboard (quadro de líderes/destaques), sistema de pontuação, recompensas, entre outros (BURKE, 2015; GEE, 2009).

A escolha dos elementos dependerá do objetivo que se quer atingir, público-alvo, habilidades a desenvolver, conteúdo a ser aprendido, meio ao qual vai ser aplicado - digital ou analógico, contexto de infraestrutura, entre outros. No que diz respeito à gamificação, o curso que aplicamos na Escola de Extensão teve o propósito de familiarizar os professores, a partir da análise de aplicativos gamificados, elaborados para fins educativos ou não. Também pretendíamos discutir os potenciais que os elementos de jogos podem trazer para o campo da educação, trazendo exemplos práticos já aplicados em sala de aula. Dessa maneira, o curso aconteceu em quatro etapas: 1) uma introdução sobre o tema; 2) apresentação de dois aplicativos gamificados que serviram de base para a terceira etapa; 3 ) atividade prática, na qual consistiu na análise de aplicativos gamificados tendo o Google formulário como guia; 4) exemplos de gamificação aplicados na educação.

Para introduzir o tema, foi discutido primeiramente o conceito de gamificação, os seus elementos e as razões pela qual a gamificação pode ser uma estratégia 
motivadora nas práticas educativas. Apesar da gamificação estar ganhando espaço na educação, apenas dois professores sabiam o seu conceito e puderam citar exemplos práticos, o que mostra a importância de se discutir o assunto com intuito de auxiliar os professores a repensar a sua prática de ensino.

Após uma breve discussão sobre o tema, apresentamos dois aplicativos, Nikeplus (+run Club) e Lingualeo, com objetivo de mostrar os elementos gamificados encontrados nessas ferramentas e, também, para prepará-los para a análise da atividade seguinte. Na terceira etapa, foi realizada uma atividade prática em que os professores em duplas deveriam analisar um aplicativo gamificado, dentre aqueles sugeridos por nós (mLearnLab, Perguntados, Mestre da matemática, ZumbiRun e Habitica) e responder um questionário através do Google Formulário. O intuito da atividade era fazer com que os professores conseguissem identificar a temática, o objetivo do aplicativo e os elementos gamificados encontrados neles. Ao final, as respostas do questionário foram compartilhadas e realizou-se um debate com os professores para conhecer suas opiniões.

De maneira geral, os professores conseguiram realizar a atividade sem grandes dificuldades, identificando os elementos e o propósito do aplicativo. É interessante salientar que no questionário e no debate, os docentes foram indagados se usariam alguns dos elementos de gamificação em sala de aula e obtivemos respostas interessantes como por exemplo, a criação de desafios, cooperação-competição entre os alunos, feedback, barra de progresso, avatares, etc. Outros disseram que não encontraram uma contextualização entre os elementos e suas atividades pedagógicas, mas que serviram para (re)pensar em suas metodologias, mostrando interesse em conhecer mais sobre o assunto.

Para finalizar o curso, mostramos exemplos de gamificação aplicada na educação, como metodologias aplicadas que trabalham com essa temática (escola Quest to learn em NY), projeto realizados que utilizam os elementos gamificados (Logus a sala do conhecimento), relatos de professores e de suas experiências utilizando a gamificação em sala como no livro multiplayer Classroom : Designing CourseWork as a game, de Lee Sheldon (2012). Essa última etapa foi que a despertou mais interesse dos professores, visto que conseguiram encontrar uma maior significação entre a teoria e prática.

A partir do curso, como já comentado anteriormente, surgiu o interesse dos participantes por um aprofundamento da discussão no que tange a aplicação do conceito no análogico, o qual se concretizou em um encontro para os professores de língua inglesa e espanhola da rede municipal de Florianópolis. Nele foram trabalhados temas como a análise da distribuição da cognição a partir do advento 
das tecnologias; a passagem dos jogos de apenas entretenimento a potencializadores de habilidades; o conceito de gamificação e experiências gamificadas e o desenvolvimento de propostas gamificadas pelos participantes.

No primeiro momento discutiu-se sobre a influência da Era Digital na sociedade e como esta afeta os dispositivos básicos de aprendizagem (atenção, memória e motivação), com o objetivo de aprofundar os conhecimentos sobre os mecanismos que estão presentes no momento do ensino/aprendizagem. Tendo isso em conta, abriu-se a discussão aos participantes se, de fato, estamos fazendo nosso papel de mediadores aos nossos alunos: conhecemos diferentes metodologias de estudos? Se sim, estamos instrumentalizando nossos alunos com diferentes abordagens para que desenvolvam sua autonomia frente à aquisição do conhecimento?

Diante dessas perguntas, a reação da maioria foi negativa. Para exemplificar e relacionar a importância do autoconhecimento no processo de aprendizagem e no planejamento da gamificação, aplicou-se o Cuestionario HoneyAlonso de Estilos de Aprendizaje (CHAEA) (ALONSO, GALLEGO, HONEY, 1999, p.79), onde os professores puderam identificar em si qual era seu perfil - ativo, pragmático, reflexivo ou teórico - e quais atividades poderiam potencializar suas habilidades ou desmotivá-los segundo suas características. Essa etapa de se conhecer, conhecer seu público e conhecer ferramentas diversificadas é fundamental na criação de projetos gamificados. Segundo Alves (2014), é importante levar em conta:

Conhecimento dos objetivos do negócio e da aprendizagem; definição dos comportamentos e das tarefas que serão alvo dessa solução; conhecimento dos jogadores; reconhecimento do tipo de conhecimento que precisará ser ensinado; garantia da presença de diversão; utilização das ferramentas apropriadas; e desenvolvimento de protótipos. (ALVES, 2014 apud SANTAELLA; NESTEURIK e FAVA, 2018 p. 15).

Nesse sentido, percebe-se que, antes de gamificar atividades, precisamos saber quais são nossos objetivos, qual o conteúdo a ser passado, se temos diferentes ferramentas para contemplar uma sala de aula diversificada, se conhecemos o que pode potencializar e o que pode desmotivar determinado perfil de turma, entre outros. Burke (2015) coloca que essa etapa visa entender as motivações dos participantes para posteriormente projetar uma experiência que possa engajá-los. E além: quando Alves (2014) fala em desenvolvimento de protótipos, significa planejar, testar e aperfeiçoar. Um dos princípios básicos da gamificação é considerar o erro como parte do processo de aprendizagem, e isso parte tanto do educador como do educando: através dos feedbacks constantes de um ao outro, possibilita-se o aperfeiçoamento tanto da metodologia como das estratégias de aquisição. 
Após essa reflexão, introduziu-se o assunto dos jogos e da definição da gamificação através de uma explicação expositiva com auxílio de vídeos para exemplificação. Seguiu-se com uma discussão sobre o porquê gamificação deveria ser considerada a partir de pontos como contexto social e geográfico, infraestrutura, desenvolvimento social, motor e cognitivo na infância e na adolescência, potencialização da autonomia estudantil (essa parte com auxílio de parte do documentário sobre o Projeto ncora), além de ressaltar-se a importância da superação de dualismos como mente x corpo, razão x emoção para a criação de experiências enriquecedoras.

A partir dessa discussão e de mostrar aos docentes estratégias para atividades gamificadas (como criar competitividade saudável através do trabalho em equipe, quais estratégias levar em conta), aplicou-se uma dinâmica em que se montou um baralho com 10 cartas. Nelas haviam "parâmetros" que os professores deveriam seguir para montar as atividades. Conforme o nível de dificuldade - identificado através das cores verde ( 2 cartas), amarelo ( 3 cartas) e vermelho (5 cartas) os participantes, junto com seus grupos, teriam que montar atividades mais ou menos complexas. Para dividir as cartas utilizou-se um dado, onde o grupo que retirasse os maiores números ficava com as cartas de menor dificuldade. Após dez minutos de montagem das atividades, cada grupo apresentou suas propostas e os outros foram incentivados a opinar sobre como fariam a atividade com turmas mais maduras ou mais jovens, se fariam algo diferente, além de trocarem experiências sobre onde conseguir certos materiais didáticos, como agiam em determinadas situações ou atividades em suas escolas.

Ao final da formação, foi pedido um feedback aos professores sobre pontos positivos e pontos a serem melhorados no curso. Todos elogiaram ambas as etapas - sobre gamificação e aplicativos - e disseram que não tinham muitas oportunidades que lhes proporcionassem prática, que o fato de poderem testar o que estava sendo proposto e discutir ideias que lhes vinham com as formadoras no momento em que estava sendo ensinado fazia com que o entendimento fosse mais facilitado, motivando-os a querer aplicar com seus alunos porque conseguiram apropriar-se daqueles recursos.

\section{CONSIDERAÇÕES FINAIS}

As tecnologias digitais não podem ser vistas como a solução de todos os problemas presentes na escola; tampouco os aplicativos ou a gamificação podem ser vistos como um fim, mas sim como meios para se chegar a determinadas metas pedagógicas, as quais nos dirão qual recurso deve ser adotado. A pretensão final de 
aprendizagem (advinda das respostas a perguntas como "o que/quais habilidades quero desenvolver com meus alunos?" "qual conteúdo quero trabalhar?" "qual é o meu objetivo final partindo desse ponto?") tem a função, portanto, de delimitar o recurso didático, e não o recurso, seja ele digital ou analógico, traçar essa pretensão.

Sendo assim, o ponto principal após todas essas experiências de formação é que os professores tenham se conscientizado e construído um pensamento crítico frente à utilização dessas novas ferramentas, não no sentido de rejeitá-las ou adotá-las como um "colete salva-vidas", mas de refletir sobre a escolha dos recursos a serem utilizados. Ou seja, que quando empregados em suas classes, essa escolha não seja feita de maneira compulsória - 'porque estou na Era Digital tenho de aplicar tecnologias digitais' - mas sim ponderando-se através de critérios didático-pedagógicos, tais como idade e nível de maturidade da turma-alvo, seus interesses pessoais e coletivos, seu contexto social (envolvendo a comunidade de onde vem, suas famílias e localização da instituição escolar em si), seu nível de identificação com o ambiente escolar (infraestrutura, professores e colegas), suas potencialidades e dificuldades de aprendizagem, entre outros que o professor observa em seu cotidiano.

\section{REFERÊNCIAS}

ALONSO, Catalina; GALLEGO, Domingo; HONEY, Peter. Los estilos de aprendizaje: Procedimientos de diagnóstico y mejora. Bilbao: Ediciones Mensajero. 1999.

ALVES, Flora. Gamification: como criar experiências de aprendizagem engajadoras. Um guia completo: do conceito à prática. São Paulo. DVS, 2014. In.: SANTAELLA, Lucia (org); NESTEURIUK, Sérgio(org); FAVA, Fabricio (org). Gamificação em debate. São Paulo. Blucher, 2018.

BANNELL, Ralph. Ings; DUARTE, Rosalia.; CARVALHO, Cristina; PISCHETOLA, Magsa; MARAFON, Giovanna; CAMPOS, Gilda Helena. (2016). Educação no século XXI: cognição, tecnologias e aprendizagens. Petrópolis, RJ: Vozes.

BURKE, Brian. Gamificar: como a gamificação motiva as pessoas a fazerem coisas extraordinárias. São Paulo: DVS, 2015. 
CETIC. Pesquisa TIC Educação 2018. Disponível em: https://cetic.br/pesquisa/educacao/ Acesso em: 10 set. 2019.

GARDNER, Howard; DAVIS, Katie. La generación app: cómo los jóvenes gestionan su identidad, su privacidad y su imaginación en el mundo digital. Ciudad Autónoma de Buenos Aires: Paidós, 2014.

GEE, James Paul. Bons videogames e boa aprendizagem. Perspectiva, v. 27, n. 1, p. 167-178, 2009.

KAPP, Karl. The Gamification of Learning and Instruction: Game-based Methods and Strategies for Training and Education. San Francisco: Pfeiffer, 2012.

KENSKI, Vani. Tecnologias e ensino presencial e a distância. Campinas: Papirus, 2003.

PÉREZ GÓMEZ, Ángel. Educação na Era Digital: a escola educativa. Tradução Marisa Guedes. Porto Alegre, Penso, 2015, 192 p.

NUNES, Gabriela Marçal. Aplicaciones para el aprendizaje de lenguas extranjeras: propuesta de adaptación de un instrumento de análisis. 2017. $50 \mathrm{f}$. TCC (Graduação) - Curso de Letras Espanhol, Departamento de Língua e Literatura Estrangeiras, Universidade Federal de Santa Catarina, Florianópolis, 2017. Disponível em: https://repositorio.ufsc.br/handle/123456789/200398. Acesso em: 25 set. 2019.

NUNES, Gabriela Marçal; BERGMANN, Juliana Cristina Faggion. Elaboração de Critérios de Análise para Aplicativos de Línguas Estrangeiras como Recursos Didáticos ao Ensino Formal. Revista Trama. v. 15, n. 35, p. 70-78, 2019. Disponível em: http://e-revista.unioeste.br/index.php/trama/article/ view/21571. Acesso em: 25 set. 2019.

NUNES, Gabriela Marçal; BERGMANN, Juliana Cristina Faggion; POLICARPO, Kadhiny Mendonça Souza; KENNER, Larissa Souza; SBEGHEN, Luana Bottcher. Docência de Línguas Estrangeiras e os Desafios da Era Digital. In: 
OLIVEIRA, L. C. de; SANTURBANO, A. P. F.; SANTOS, B. C. M. dos; FERREIRA, C. P.; SOARES, N. G. (Org.). Língua, Literatura, Tradução: pluralidades. 1ed. Curitiba: CRV, 2019, v. 1, p. 17-26.

SCHMIDT, Eric; COHEN, Jared. A nova era digital: como será o futuro das pessoas, das nações e dos negócios. Rio de Janeiro: Intrínseca, 2013.

VAZQUEZ-CANO, Esteban; SEVILLANO, Maria Luisa (org) Dispositivos Digitales Móviles en Educación. El aprendizaje ubicuo. 2 ed. Madrid: Narcea, 2019.

VEEN, Wim; VRAKKING, Ben. Homo Zappiens: educando na era digital. Trad. de Vinícius Figueira. Porto Alegre: Artmed, 2009. 141 p. 